\title{
Take-over request
}

\author{
Driverless cars are improving, but is the public ready to accept them?
}

utonomous vehicles have the potential to make roads safer, to reduce carbon emissions and to help improve access to transportation. Car and tech companies around the globe have been exploring the technology for years and capabilities have become increasingly sophisticated (though perhaps not at the rate many had predicted or promised ${ }^{1}$ ). But the future of driverless cars will depend on more than just a maturing of the technology - the public's appetite for such vehicles will also determine their success or failure.

Funding has flowed into the research and development of autonomous vehicles. However, efforts to build trust in the technology are often overlooked. A recent poll $^{2}$ commissioned by the advocacy group Partners for Automated Vehicle Education highlights that the wider public is still sceptical about autonomous vehicles. Almost half of Americans that took part in the poll said that they "would never get in a taxi or ride-share vehicle that was being driven autonomously" and a fifth believe that the vehicles will never be safe. Similar scepticism has been observed in surveys of drivers in Germany and, to a lesser extent, drivers in Japan and China ${ }^{3}$. Building trust in autonomous vehicles should be a priority for the industry.

In a Comment article in this issue of Nature Electronics, Cristina Olaverri-Monreal explains that in order to establish public trust it is important to understand how different road users drivers, passengers, pedestrians - react to the vehicles, which create unfamiliar situations for many. A person's trust will depend on feeling safe and verifying that the technology functions as it should. It is therefore essential, she argues, that road users' expectations are taken into account during product development. The design of simple and intuitive interfaces will also be critical, and studies have, for example, shown that driverless cars that have features that can create human-like forms of communication between a vehicle and a road user (an interface that can smile at a pedestrian, for example) are perceived positively.

First-hand experiences with driverless vehicles, familiarity with their features, and an understanding of the limitations of

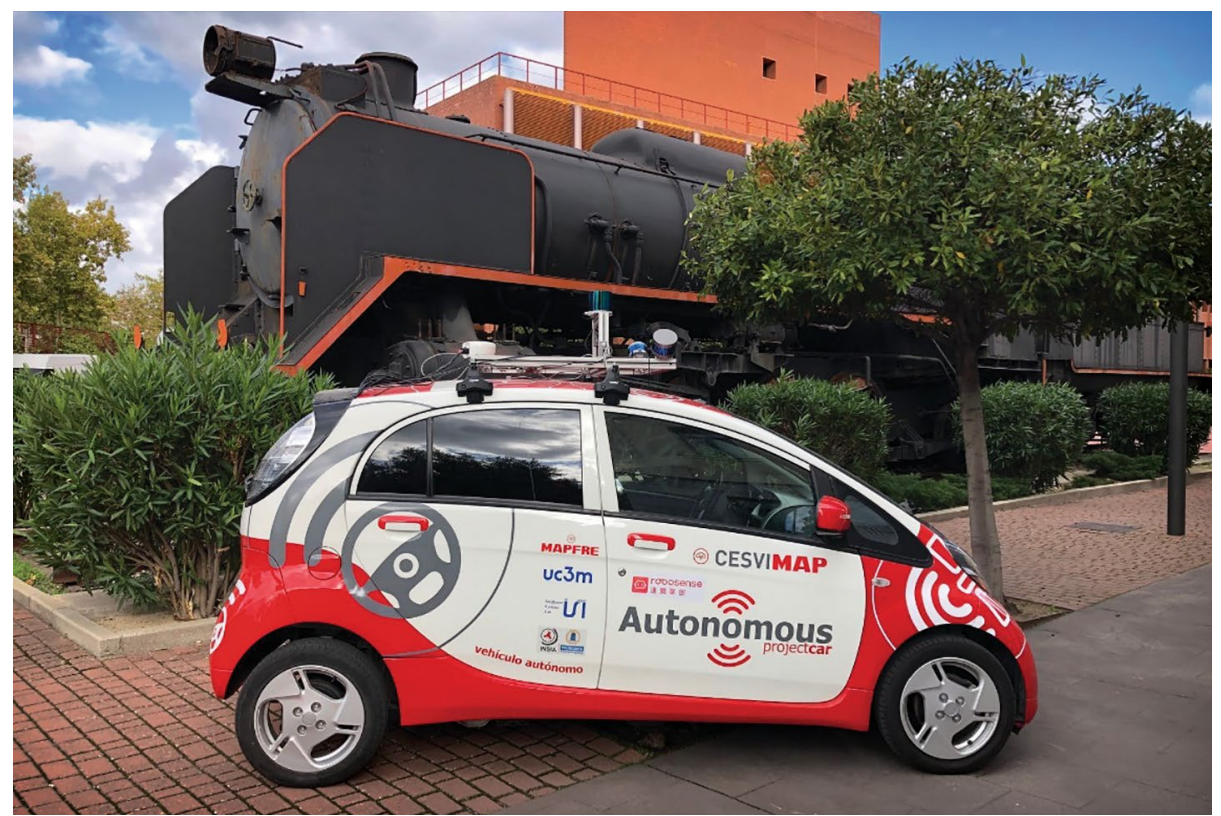

A self-driving car used for autonomous vehicle research. The vehicle was developed by the Intelligent System Lab of the Universidad Carlos III de Madrid, INSIA and CESVIMAP. Credit: CESVIMAP

the technology can all help change public perceptions of the technology. In fact, drivers that already use driver assistance features in their own cars appear more positive about automation ${ }^{4}$. But at the same time, the complex terminology used by the autonomous vehicle community, and the lack of education within the wider public about what it represents, can put people off.

Beyond issues of trust and engineering, legislative and ethical challenges also remain to be solved before highly automated vehicles are widely available to consumers. Nevertheless, semi-automated vehicles can currently be found in both controlled sites and public roads, and are increasingly finding application in specialized tasks. The current coronavirus pandemic has also shifted the landscape. Testing of self-driving cars has been suspended in the US, but self-driving taxis - robotaxis - are being tested in China ${ }^{5}$. Companies involved in the autonomous delivery of goods and food have also seen increased funding ${ }^{6}$, as the everyday requirements for many people across the world have changed.

The intelligent capabilities currently being developed for cars can also be put to use in other ways. In a Comment article elsewhere in this issue, Fernando Ascensão, Cristina Branquinho and Eloy Revilla argue that cars - together with appropriate communications technology and machine learning algorithms - could create a global network of moving sensors that monitor and protect biodiversity, as well as help improve driver safety.

Published online: 22 June 2020

https://doi.org/10.1038/s41928-020-0440-x

References

1. Metz, C. \& Griffith, E. This was supposed to be the year driverless cars went mainstream. The New York Times (12 May 2020); https://go.nature.com/3eYGTkT

2. PAVE Poll: Americans Wary of AVs but Say Education and Experience with Technology can Build Trust (PAVE, 2020), https://go.nature.com/3difcmy

3. Continental Mobility Study 2018 (Continental AG, 2018); https://go.nature.com/2zibDhA

4. Choi, S., Thalmayr, F., Wee, D., \& Weig, F. Advanced Driver-Assistance Systems: Challenges and Opportunities Ahead (McKinsey \& Co., 2016); https://go.nature.com/2YawgVs

5. Shepherd, C. China's self-driving car projects accelerate during coronavirus. The Financial Times (19 May 2020); https://go.nature.com/2XJL26c

6. Lienert, P. \& Lee, J. L. Automated delivery cashes in on pandemic-driven demand. Reuters (18 May 2020); https://go.nature.com/2MzwsYZ 